\title{
POLÍTICAS ATUAIS PARA FORMAÇÃO DE PROFESSORES DA EDUCAÇÃO BÁSICA E AS NOVAS DIRETRIZES NACIONAIS PARA A FORMAÇÃO DOCENTE
}

\author{
Maria Eunice França Volsi ${ }^{1}$, Jani Alves da Silva Moreira ${ }^{2}$, Gislaine Aparecida Valadares Godoy ${ }^{3}$ \\ ${ }^{1}$ Doutora em Educação pela Universidade Estadual de Maringá - UEM. Professora do Departamento de Teoria e Prática da Educação da UEM, \\ Maringá, PR. E-mail: mefvolsi@uem.br \\ ${ }^{2}$ Doutora em Educação pela Universidade Estadual de Maringá - UEM. Professora do Departamento de Teoria e Prática da Educação e do Programa \\ de Pós-Graduação em Educação (PPE/UEM), Maringá, PR. \\ ${ }^{3}$ Doutoranda pelo Programa de Pós-Graduação em Educação Universidade Estadual de Maringá - UEM. Professora do Departamento de Pedagogia \\ da UEM, Campus Regional de Cianorte, PR.
}

\section{RESUMO}

O presente texto apresenta uma reflexão sobre os novos desafios para a formação de professores da Educação Básica mediante as reformas políticas em andamento, instituídas pelas Diretrizes Curriculares Nacionais para a formação inicial e continuada dos profissionais do magistério da educação básica, documentadas nas orientações do Parecer CNE/CP nำ2/2015 e regulamentadas pela Resolução CNE/CP no 2/2015. É objetivo do texto apresentar o impacto na organização curricular dos cursos de licenciatura a partir dessas diretrizes, bem como a articulação entre as instituições formadoras e a Educação Básica. 0 encaminhamento metodológico se deu por meio da pesquisa bibliográfica e documental, no qual o referencial teórico compreende o objeto à luz da materialidade histórica, no contexto atual das transformações ocorridas no mundo do trabalho. O estudo sinaliza os novos caminhos e os possíveis impactos da política de formação de professores no Brasil, as ações de governo nessa área e as interfaces com outras dimensões das políticas educacionais no contexto atual.

Palavras-chave: Educação Básica; Política Educacional; Formação de Professores; Diretrizes Curriculares.

\section{CURRENT POLICIES FOR THE TEACHER TRAINING IN BASIC EDUCATION AND THE NEW NATIONAL GUIDELINES FOR TEACHER TRAINING}

\begin{abstract}
The present text introduces a reflection on the new challenges for the Teacher Training for Basic Education through the policies in definition established by the National Curricular Guidelines for the initial and continued training of teachers of the basic education teaching profession, documented in the guidelines of Opinion CNE/CP no2/2015 and regulated by Resolution CNE/CP no 2/2015. It is the purpose of the text to present the impact on the curricular organization of undergraduate courses from these guidelines, as well as the articulation between the teacher training institutions and the Basic Education. The methodological guidance was made through bibliographical and documentary research. The study indicates the new ways and possible impacts of the policy of teacher training in Brazil, government actions in this area and the interfaces with other dimensions of educational policies in the current context.
\end{abstract}

Keywords: Basic Education; Educational Politics; Teacher Training; Curricular Guidelines.

INTRODUÇÃO

"Os homens fazem sua própria história, mas não a fazem como querem; não a fazem sob circunstâncias de sua escolha e sim, sob aquelas com que se defrontam diretamente, legadas e transmitidas pelo passado" (MARX, 2003, p.7).

A formação inicial e continuada de professores da educação básica tem sido tema recorrente no meio acadêmico devido às reivindicações por melhoria na qualidade da 
educação básica no País ${ }^{1}$. Com intuito de promover políticas destinadas a essa formação foi aprovado em julho de 2015, as novas Diretrizes Curriculares para a formação de professores, em nível superior. Trata-se da Resolução no 2, de 1ㅇ de julho de 2015, que define as Diretrizes Curriculares Nacionais para a formação inicial em nível superior, nos cursos de licenciatura, cursos de formação pedagógica para graduados e cursos de segunda licenciatura e, também, para a formação continuada de professores. Essas novas diretrizes orientam para a organização curricular da formação inicial e continuada dos professores da educação básica e se apresenta como elemento norteador no desenvolvimento de políticas formativas com o intuito de melhorar a qualidade do nível educacional superior nas licenciaturas, pósgraduação e em programas de formação continuada no país.

Diante do exposto, salienta-se que o presente texto tem por objetivo refletir sobre as orientações expressas nessa nova diretriz curricular a fim de trazer à tona algumas interpretações dessa nova reforma que orientam as políticas para formação de professores. A temática é relevante para o contexto de incessantes mudanças decorrentes da crise e dos retrocessos no campo educacional, especificamente a partir de 2015, a fim de identificar os impactos na organização curricular dos cursos de licenciatura.

Refere-se a uma investigação documental no qual os documentos oficiais foram analisados levando-se em consideração o momento histórico de sua produção. Prioriza-se que o objeto de estudo seja contextualizado no tempo e no espaço histórico em que foi produzido, procedendo assim, a mediação entre as esferas do singular e do universal.

Parte-se do desígnio de que as políticas para a formação de professores, atualmente concretizadas no Brasil, se constituem em representações históricas, com significações que expressam aspectos ideológicos produzidas no contexto de mundialização da economia, na fase de vigência da acumulação financeirizada,

\footnotetext{
${ }^{1}$ Em uma rápida busca no Catálogo de Teses e Dissertações da CAPES é possível identificar até a data de 23 de janeiro de 2018, 987.217 resultados para o descritor "formação inicial e continuada de professores da educação básica", sendo que foram produzidas 696390 dissertações e 228284 teses de Doutorado. Somente no ano de 2016 encontramos 80.591 pesquisas. Na área do conhecimento Educação tivemos 42.418 teses e dissertações (CATÁLOGO TESES E DISSERTAÇÕES CAPES, 2018).
}

flexível e do neoliberalismo. Desenhada por esse contexto, a educação e suas reformas:

[...] trazem embutidas em sua concepção: uma escola (e uma "educação") flexibilizada para atender as exigências e os imperativos empresariais; uma formação volátil, superficial e adestrada para suprir as necessidades do mercado de trabalho "polivalente", "multifuncional" e flexível (ANTUNES, 2017, p. 12).

Torna-se fundamental investigar nos documentos oficiais como a ideologia neoliberal, com sua lógica racional e precisa, estabelece e se articula em ações levando-se em consideração o contexto particular em que foram produzidos. Considera-se que "[...] os textos são, ao mesmo tempo, produtos e produtores de orientações políticas no campo da educação, sua difusão e promulgação geram também situações de mudanças ou inovações, experienciadas no contexto das práticas educativas" (SHIROMA; CAMPOS; GARCIA, 2005, p. 433). Contudo, na análise apresentada considera-se o contexto social-econômico no período retratado e se refere aos resultados de uma investigação, no qual as pesquisadoras estudam essa temática no Grupo de estudos e pesquisa em Políticas Educacionais, Gestão e Financiamento da Educação (GEPEFI/CNPq).

Para dar conta do proposto, inicialmente, apresenta-se um panorama do contexto histórico em que se assenta o processo de definição da política para a formação de professores no país, a fim de evidenciar a legislação recente que estabelece e normatiza as políticas para formação de professores, especificamente, da Educação Básica. $\mathrm{Na}$ sequência, elucida-se sobre o conteúdo da diretriz que incide diretamente na organização curricular dos cursos de formação inicial e continuada de professores, bem como, destaques da Política Nacional de Formação de Professores. Por fim, apreende-se algumas considerações pertinentes sobre as implicações e impactos dessa política em implementação nas instituições de Ensino Superior que ofertam formação de professores inicial e continuada. 
Contexto histórico e legal: o processo de definição da política para a formação de professores

Ao analisar as mudanças na política para formação de professores da Educação Básica em andamento faz-se necessário compreender esse contexto a partir de um exame intenso que tem suas origens em um universo mais amplo, proveniente desde a crise que atingiu o capitalismo no início da década de 1970, no qual a crise por meio do excesso de produção e o esgotamento do padrão de produção tayloristafordista foi manifestação de uma crise estrutural do sistema capitalista (MÉSZÁROS, 2002; MOREIRA, 2012, 2015; ANTUNES, 2017; SILVA JÚNIOR, 2017).

Nesse contexto, o modo de produção capitalista passou a dar sintomas de um quadro crítico observado pela tendência decrescente da taxa de lucro, pela desvalorização do dólar e, consequentemente, a falência de Bretton Woods e a crise do Welfare State, com a intensificação das lutas sociais e a crise do petróleo. Instalados esses sintomas de crise estrutural do capital, as décadas de 1980 e 1990 seguiram com modificações em sua estrutura social que deterioraram, progressivamente, as condições de vida da maioria da população do planeta, com um quadro de desemprego em massa, rendimentos das classes populares rebaixados, e ainda:

Seria preciso acrescentar os efeitos humanos do fechamento das fronteiras dos países mais industrializados aos fluxos migratórios, da degradação do meio ambiente (efeito estufa, poluição,

desflorestamento

maciço...) e da desregulamentação da produção alimentar (TOUSSAINT, 2002, p. 4142).

Antunes (2004) explicita que no Brasil, em um ritmo mais lento do que nos países centrais, durante a década de 1980 foram presenciadas modificações organizacionais e tecnológicas no interior do processo produtivo e de serviços. No período do governo Sarney (1985-1990) o Brasil apresentava os primeiros influxos da nova divisão internacional do trabalho e passava a ser afetado pelos "[...] novos traços universais do sistema global do capital, desenhando uma particularidade brasileira diferenciada" (ANTUNES, 2004, p. 16). Nessa década ocorreram os primeiros impulsos do processo de reestruturação produtiva no Brasil:

[...] levando as empresas a adotarem, inicialmente de modo restrito, novos padrões organizacionais e tecnológicos, novas formas de organização social e sexual do trabalho. Observou-se a ampliação da informatização produtiva, principiaram-se os usos do sistema just-in-time, da produção baseada em team work, nos programas de qualidade total, ampliando também o processo de difusão da microeletrônica. Deu-se o início, ainda também preliminar, dos métodos denominados participativos, mecanismos que procuram o envolvimento dos trabalhadores nos planos das empresas (ANTUNES, 2004, p. 16).

Diante do processo de reestruturação produtiva, o capital procurou restabelecer o padrão de acumulação e mostrou os sintomas de uma nova configuração e dinâmica da produção e acumulação do capital no contexto de Mundialização do Capital. Chesnais (1997) assinala que as políticas de caráter neoliberal, tais como a liberalização do comércio e da produção, a desregulamentação da economia e a privatização das empresas que os Estados capitalistas justificam como forma de ampliação da liberdade de o capital mover-se e desdobrarse à vontade internacionalmente. $\mathrm{O}$ capitalismo financeiro internacional inaugurou uma crise estrutural que propiciou um acirramento no ciclo de contradições do capital, com a reestruturação produtiva. A lógica do neoliberalismo e a democracia global como instrumento desses ditames reforçaram a vertente de pensamento de que para se reorganizar, o capital urge por mudanças, por 
reformas estruturais: os chamados ajustes estruturais.

Soares (2003, p. 19) assevera que os ajustes estruturais feitos sob a égide da doutrina neoliberal produziram as políticas neoliberais na educação. Portanto, são "políticas de ajuste que fazem parte de um movimento de ajuste global que se desenvolve num contexto de globalização financeira e produtiva". Esse processo de ajuste estrutural, na visão da autora, gera agravamento das desigualdades e aumento da exclusão, podendo até ser denominado desajuste social por meio do agravamento das condições de desigualdade estrutural, como também gerou novas condições de exclusão social e generalização da precariedade em diversos setores sociais.

No bojo dos incessantes ajustes estruturais neoliberais, o Estado configurou-se como Estado mínimo para a área social. Foi apregoada ao Estado a necessidade de reformulações em suas ações e políticas. 0 conceito de Estado diante da perspectiva teórica que permeia as análises desta proposta de pesquisa tem como base: a) que o Estado não pode ser entendido por si mesmo, mas nas relações materiais de existência, pois o modo de vida material determina os processos sociais, político e espiritual (MARX; ENGELS, 1986); b) o Estado é histórico, concreto, de classe. É o Estado máximo para o capital, pois no processo de correlação de forças é o capital que detém a hegemonia; e c) As mudanças constitutivas na política educacional são parte da materialidade da redefinição do papel do Estado.

O processo de mercantilização e financeirização da educação tomou corpus a partir da reforma do Estado ocorrida no Brasil como uma proposta alternativa capaz de liberar a economia para uma nova etapa de crescimento econômico. Por meio da influência do neoliberalismo disseminou-se a valorização de uma política pautada na revalorização do mercado - uma retomada atualizada dos princípios do liberalismo. Na área social, a redução do papel do Estado caracterizou-se na mercantilização dos serviços sociais, uma ação pouco recomendável que deveria ser substituída pela atuação do setor privado - o chamado terceiro setor da economia. Nesse enfoque, a "[...] mercantilização dos serviços sociais mesmo os essenciais, como saúde e educação também é vista como 'natural': as pessoas devem pagar pelos serviços para que estes sejam 'valorizados'” (SOARES, 2003, p. 12).

A reestruturação produtiva do capital tornou os Estados ameaçados em seu poder autônomo. Mesmo assim, estes mantiveram o poder de disciplinar o trabalho e "intervir nos fluxos de mercados financeiros, porém tornaram-se vulneráveis a crises fiscais e à disciplina do dinheiro internacional" (HARVEY, 1992, p. 181).

Resultado desse processo intenso de reestruturação de acumulação flexível, as políticas de ajustes estruturais neoliberais e a reforma do Estado, culminam ao que estamos presenciando:

[...] como as profundas
repercussões no mundo
do trabalho em escala
global. O trabalho [...]
está sendo substituído
pelas diversas formas de
"empreendedorismo",
"cooperativismo",
"trabalho voluntário",
"trabalho atípico",
"intermitente", formas
que acentuam a
superexploração do
trabalho, configurando o
que denominei como
tendência crescente à
precarização estrutural
da força de trabalho em
escala global (ANTUNES,
2017, p. 05).

Diante do exposto, a formação de professores da Educação Básica se reafirma nesse contexto como caráter de urgência para ser modificada em atendimento às novas demandas do mundo do trabalho, inserida, portanto, no projeto de educação que o capital está a produzir nessas primeiras duas décadas do século XXI. Vivencia-se um período denominado por Antunes (2017) de liofilização ${ }^{2}$ ao referir-se a nova empresa flexível toyotista da

\footnotetext{
2 Antunes (2017, p. 07) esclarece que a expressão liofilização, "utilizada por Juan J. Castillo, não é um termo das Ciências Sociais, cabe aqui uma explicação rápida: na Química, liofilizar significa, em um processo de temperatura baixa, secar as substâncias vivas. 0 leite em pó é um leite liofilizado. Nos referimos, portanto, aqui, à secagem da substância viva que, na empresa, é o trabalho vivo, que produz coisas úteis, riqueza material e valor, e que contraditoriamente se reduz no capitalismo."
} 
atualidade. No qual se exige cada vez mais trabalhadores déspotas de si mesmo ${ }^{3}$, assim:

A empresa flexível só pode existir, então, com base no envolvimento, na expropriação do intelecto do trabalho. Por isso passou a ser comum exigir-se dos/as trabalhadores/as não apenas a execução de variadas tarefas (operação e manutenção dos equipamentos, limpeza e organização do local de trabalho, controle de qualidade etc.), como ainda a responsabilidade de se reunir continuamente com a gerência sugerindo melhorias nos processos de maneira a cortar estoques e elevar a produtividade (ANTUNES, 2017, p. 07).

$\mathrm{Na}$ educação as determinações se amparam em processos de aprendizagem flexível para a formação de profissionais flexíveis que acompanham as mudanças contemporâneas da produção científico-tecnológica, na qual se exige uma qualificação profissional pautada em experiências práticas centradas em atividades do chamado "conhecimento tácito", maior autonomia, criatividade, a pedagogia do aprender a aprender (KUENZER, 2016; ANTUNES, 2017). Desse modo, pretende-se promover uma reengenharia na formação de professores e estabelecer "uma educação enxuta para empresas que contam com cada vez menos trabalhadores/as" (ANTUNES, 2017, p. 12). Sob esse desígnio é que as reformas curriculares e a formação de professores para a Educação Básica têm sido pautadas, conforme alerta o autor:

[...] sob a vigência do toyotismo e sua organização flexível, o ensino deve ser baseado na desespecialização "multifuncional". É por isso que, no contexto atual, as instituições de ensino (sobretudo o

\footnotetext{
3 Expressão utilizada por Antunes (1995), na obra Adeus ao trabalho.
}

ensino técnico, mas também o superior, principalmente se voltado às engenharias) têm buscado adaptar seus currículos a um contexto no qual os trabalhadores/as devem ser mais flexíveis, "polivalentes", ao operarem equipamentos cada vez mais avançados, com ênfase nas tecnologias digitais e de informação (ANTUNES, 2017, p. 11).

Com relação à legislação definida nesse contexto, a formação inicial e continuada de professores estão previstas na Lei de Diretrizes e Bases da Educação Nacional (LDBEN), Lei n. 9.394/96, no Plano Nacional de Educação (PNE) de 2001 (Lei n. 10.172/2001), bem como no PNE atual, aprovado em 2014 pela Lei n. 13.005 para o período de 2014 a 2024. O contido na lei é resultado de muitos embates e enfrentamentos entre movimentos e fóruns da sociedade civil organizada, associações e entidades educacionais junto ao Ministério da Educação e Conselho Nacional de Educação. A definição de uma política envolve diversas etapas e passa por mecanismos de regulação.

Além dos princípios, a LDBEN estabelece também, a formação exigida para o exercício do magistério da educação básica, bem como, a formação inicial e continuada desses profissionais. Depreende-se do contido na lei que a formação inicial e continuada dos profissionais do magistério deve ocorrer em regime de colaboração entre a União, Estados e Municípios que são por esta norma, responsáveis pela normatização e promoção da referida formação. Tem-se estabelecido que a formação inicial de professores deverá ser em nível superior, em cursos de licenciatura, de graduação plena. Destaca-se, no entanto, a admissibilidade do ensino médio modalidade normal, como formação mínima para o exercício do magistério na educação infantil e anos iniciais do ensino fundamental (BRASIL, 1996).

Como norma geral de organização da política educacional brasileira o anterior Plano Nacional de Educação de 2001 estabeleceu como objetivos e metas destinadas aos profissionais da educação, diretrizes curriculares 
para os cursos superiores de formação de professores e de profissionais da educação para os diferentes níveis e modalidades de ensino.

Decorrente dessa norma, o Conselho Nacional de Educação elaborou a Resolução CNE/CP 1/2002 (BRASIL, 2002), que fixava as Diretrizes Curriculares Nacionais (DCNS) para a formação de professores da Educação Básica, em nível superior, curso de licenciatura, de graduação plena. Trata-se de um conjunto de princípios, fundamentos e procedimentos que devem ser observados na organização institucional e curricular das instituições de ensino superior que ofertam cursos de licenciatura para todos os níveis e modalidade da educação básica. De acordo com o Parecer CNE/CP n. 9/2001, as referidas diretrizes tinham como objetivo propor uma base comum de formação docente baseada em competências, a serem desenvolvidas ao longo do processo formativo no ensino superior (BRASIL, 2001).

Embora reconhecida como uma conquista em termos de definição de política curricular a nível nacional, muitas foram as críticas tecidas em relação aos fundamentos das DCNS para formação de professores em nível superior. A principal delas reside na ênfase ao desenvolvimento de competência no processo formativo (FREITAS, 2002, 2007; SCHEIBE; BAZZO, 2013).

De acordo com Scheibe e Bazzo (2013) a partir dos pressupostos e orientações emanadas das DCNS de 2002, nasceu a exigência de uma reconstrução na organização e desenvolvimento dos cursos de Licenciatura, bem como, a necessidade de mudanças de concepção dos formadores. As instituições de formação de professores passaram a discutir e implementar reformas nas estruturas curriculares dos cursos de licenciaturas, no sentido de atender às normas legais. Ainda conforme as autoras é preciso considerar as descontinuidades das reformas educativas destinadas aos professores influenciadas por inúmeros fatores políticos e culturais:

Dentre eles destacam-se, de um lado, a ausência de uma política de Estado que assuma sua responsabilidade pela formação inicial dos professores com a qualidade requerida pelo mundo contemporâneo. De outro, o pathos institucional revelado, entre outros indicadores,

pela força de posicionamentos

rigidamente

estratificados em relação

à natureza e ao valor do conhecimento científico e ao papel social da educação superior voltada a formar professores, colocando esta última tarefa em situação francamente subalterna àquela. É importante observar que tal posicionamento é consentâneo a posturas político-institucionais que privilegiam o trabalho acadêmico de investigação e produção do conhecimento, em detrimento do trabalho da docência (SCHEIBE; BAZZO, p.23, 2013).

Discussões dessa natureza acompanharam todo o processo de elaboração de políticas para a formação docente desde a publicação das DCNS de 2002. Fizeram parte e orientaram a elaboração das Diretrizes Curriculares dos diversos cursos de licenciatura no País. Cabe salientar, que esse processo de reestruturação dos cursos para atender as Diretrizes de 2002 se constituíram em um processo longo e permeado de ações a serem desenvolvidas, que em sua maioria, não dependiam das instituições formadoras e sim de políticas e ações de iniciativa da União.

Em 2 de julho de 2015 foi publicada no Diário Oficial da União a Resolução n. 2, de 1 ㅇ de julho de 2015, que define as Diretrizes Curriculares Nacionais para a formação inicial em nível superior (cursos de licenciatura, cursos de formação pedagógica para graduados e cursos de segunda licenciatura) e para a formação continuada. Essa Diretriz é que norteará a partir da data de publicação, os cursos de formação de professores e, diferentemente da anterior, estabelece prazo, inicialmente, de dois anos, prorrogado recentemente, para três anos ${ }^{4}$, para que as instituições de ensino superior façam as devidas

\footnotetext{
${ }^{4}$ Conforme Resolução CNE/CP n. 01, de 09 de agosto de 2017
} 
adequações em seu Projeto Pedagógico Institucional (PPI), Projeto Pedagógico do Curso (PPC) e Projeto de Desenvolvimento Institucional (PDI).

Embora tenha sido aprovada e publicada em 2015, a Comissão bicameral composta por membros da Câmara de Educação Básica e Câmara do Ensino Superior do Conselho Nacional de Educação discutia a matéria desde 2004. Durante esses doze anos, conforme explica Aguiar (2015), vários foram os titulares do Ministério da Educação, o que implicou em sucessivas mudanças de equipe das secretarias executivas e de órgãos vinculados ao MEC. Várias foram também, a recomposição da Comissão Bicameral de Formação de Professores ${ }^{5}$ designadas pelo CNE.

Conforme Dourado (2015a, p.304) "[...] a formação de profissionais do magistério da educação básica tem se constituído em campo de disputas de concepções, dinâmicas, políticas, currículos". E esses embates se intensificam nos momentos em que se discute a elaboração de documentos orientadores e normatizadores da política nacional de educação. Nos últimos anos pudemos constatar a intensa participação das entidades, associações e fóruns educacionais na Conferência Nacional da Educação Básica (CONEB) em 2008, nas Conferências Nacionais de Educação (CONAE) em 2010 e 2014, bem como no processo de elaboração e tramitação de legislações atinentes aos profissionais da educação.

Aguiar (2015, p. 247) assevera que as DCNS para o Magistério da Educação Básica "atendem parte das demandas históricas das entidades acadêmicas do campo educacional, envolvidas com o debate sobre a formação dos profissionais da Educação".

Em suas considerações preliminares a Resolução CNE/CP n. 2/2015 destaca, entre outras questões, que é indispensável para o projeto nacional de educação brasileira a consolidação das normas nacionais para a formação de profissionais do magistério da educação básica, em seus níveis e modalidades; a superação da fragmentação das políticas

\footnotetext{
${ }^{5}$ Como demonstram as Portarias e Ata: Portaria CNE/CP no 2, de 15 de setembro de 2004; Portaria CNE/CP no 3, de 20 de setembro de 2007; Portaria CNE/CP no 1, de 9 de outubro de 2008; Portaria CNE/CP no 9, de 10 de junho de 2009; Portaria CNE/CP no 1, de 18 de junho de 2010; Ata no 14 da reunião do CP/CNE em 4 de setembro de 2012; Portaria CNE/CP no 1, 28 de janeiro de 2014; Portaria CNE/CP no 6, de 2 de dezembro de 2014 (BRASIL, 2015a, p. 2).
}

públicas e a desarticulação institucional por meio da instituição do Sistema Nacional de Educação; a necessidade de articulação entre as Diretrizes Curriculares Nacionais para a Formação Inicial e Continuada, em Nível Superior, e as Diretrizes Curriculares Nacionais da Educação Básica (BRASIL, 2015b).

Com a efetivação da Base Nacional Comum Curricular (BNCC), salienta-se que os cursos de licenciatura deverão observar o que é estabelecido como base às áreas de conhecimento para se adequarem as novas demandas de formação dos professores da Educação Básica no País. Essa situação de delonga tem levado muitas instituições a protelarem a reestruturação dos cursos, bem como, a instituição do Sistema Nacional de Educação que defina e regulamente o regime de colaboração na organização da política nacional de formação e valorização de professores no Brasil.

Com relação às DCNS para formação inicial e continuada de professores, esta se encontra organizada em oito capítulos assim distribuídos: Nas disposições gerais instituem-se as DCNS para formação inicial e continuada em Nível Superior de Profissionais do Magistério da Educação Básica, para todos os níveis e modalidades, em que são definidos "os princípios, fundamentos, dinâmica formativa e procedimentos a serem observados nas políticas, na gestão e nos programas e cursos de formação, bem como no planejamento, nos processos de avaliação e de regulação das instituições de educação que as ofertam" (BRASIL, 2015b, Art. 1ํ). O Artigo 1ำ, parágrafo 2o estabelece que:

Art. 1ㅇ…]

$\S$ 2을 instituições de ensino superior devem conceber a formação inicial e continuada dos profissionais do magistério da educação básica na perspectiva do atendimento às políticas públicas de educação, às Diretrizes Curriculares Nacionais, ao padrão de qualidade e ao Sistema Nacional de Avaliação da Educação Superior (Sinaes), manifestando organicidade entre o seu Plano de 
Desenvolvimento

Institucional (PDI), seu Projeto Pedagógico Institucional (PPI) e seu Projeto Pedagógico de Curso (PPC) como expressão de uma política articulada à educação básica, suas políticas e diretrizes (BRASIL, 2015b).

As novas DCNS preveem a possibilidade de formação por meio dos Centros de Formação de estados e municípios e também de instituições educativas de educação básica. Mas, independentemente do local onde ocorra a formação inicial e continuada estas devem atender as políticas públicas de educação, as Diretrizes Curriculares Nacionais, ao padrão de qualidade a ao Sistema Nacional de Avaliação da Educação Superior (SINAES). Devem expressar desse modo, uma organicidade entre seu Plano Institucional, o Projeto Político Pedagógico (PPP) e o Projeto Pedagógico de Formação Continuada (PPFC) (BRASIL, 2015b).

Ainda nas disposições gerais, Artigo 3ㅇ, parágrafo 60 é previsto que 0 projeto de formação deve ser elaborado e desenvolvido por meio da articulação entre a instituição de educação superior e o sistema de educação básica envolvendo a consolidação de fóruns estaduais e distritais permanentes de apoio à formação docente.

Quanto à Base Comum Nacional para a formação dos profissionais do magistério para a educação básica, o capítulo II da Resolução, em seu Artigo 5o define que:

Art. 5o A formação de profissionais do magistério deve assegurar a base comum nacional, pautada pela concepção de educação como processo emancipatório e permanente, bem como pelo reconhecimento $\mathrm{da}$ especificidade do trabalho docente, que conduz à práxis como expressão da articulação entre teoria e prática e à exigência de que se leve em conta a realidade dos ambientes instituições educativas da educação básica e da profissão (BRASIL, 2015b).

Essa formação será possível à medida que houver uma articulação sistemática entre a organização dos cursos de licenciatura no Ensino Superior e a Educação Básica. O que se espera dos/as egressos/as dos cursos de formação inicial e continuada conforme disposto no capítulo III da resolução, é que possuam os conhecimentos necessários ao desenvolvimento de uma prática educativa de qualidade socialmente referenciada. Nesse sentido, tanto o Parecer CNE/CP n-2/2015, quanto a Resolução CNE/CP n-2/2015 especificam que o(a) egresso(a) da formação inicial e continuada deverá possuir informações e habilidades resultantes da pluralidade de conhecimentos teóricos e práticos, resultado do projeto pedagógico e do percurso formativo vivenciado cuja consolidação virá do seu exercício profissional, fundamentado em princípios e interdisciplinaridade, contextualização, democratização, pertinência e relevância social, ética e sensibilidade afetiva e estética (BRASIL, 2015a, 2015b).

Ao tratar especificamente da formação inicial para os profissionais do magistério da educação básica, em nível superior, o capítulo IV detalha quais são esses cursos: cursos de graduação de licenciatura; cursos de formação pedagógica para graduados não licenciados; cursos de segunda licenciatura. E explica que a instituição formadora deverá definir no seu projeto institucional as formas de desenvolvimento da formação inicial dos profissionais do magistério da educação básica. Essa abrangência da formação inicial tem sido desenvolvida por meio do Plano Nacional de Formação dos Professores da Educação Básica $\left(\right.$ PARFOR) ${ }^{6}$. Esse Plano tem como objetivo estabelecer ações e metas para atender à

\footnotetext{
${ }^{6}$ O PARFOR concluirá as turmas em andamento e será extinto. Em substituição, foi anunciado pelo diretor da CAPES, Marcelo Câmara, o Programa de Formação Inicial e Continuada para Professores da Educação Básica (Profic). De acordo com o diretor, o novo programa vai atualizar o modelo do Plano Nacional de Formação de Professores da Educação Básica (Parfor). Entre as mudanças destaca-se: os recursos financeiros serão repassados diretamente às instituições; mudança nos currículos dos cursos que deverão focar nos professores que estão em sala de aula; a experiência dos professores tem que ser contemplada na formação. Disponível em: http://capes.gov.br/sala-de-imprensa/noticias/8567-formacao-deprofessores-em-atividade-tera-novo-modelo. Acesso em 24/10/2017.
} 
demanda por formação inicial e continuada dos professores das redes públicas de Educação Básica em caráter emergencial. Trata-se de uma medida decorrente da Política Nacional de Formação dos Profissionais do Magistério da Educação Básica, instituída pelo Decreto $\mathrm{n}$. $6.755 / 2009^{7}$.

De acordo com Freitas (2013), o Decreto no 6.755 representou um ganho político importante para a formação de professores, no entanto argumenta que se trata de uma política emergencial para atender à demanda de formação de professores em exercício que não possuem formação em nível superior ou formação na área em que atuam.

Com o intuito de garantir diretrizes articuladas à trajetória das instituições formadoras, define-se que os cursos de formação inicial, respeitadas a diversidade nacional e a autonomia pedagógica das instituições serão constituídos dos seguintes núcleos: I- núcleo de estudos de formação geral, das áreas específicas e interdisciplinares, e do campo educacional, seus fundamentos e metodologias, e das diversas realidades educacionais; II- núcleo de aprofundamento e diversificação de estudos das áreas de atuação profissional, incluindo os conteúdos específicos e pedagógicos, priorizadas pelo projeto pedagógico das instituições, em sintonia com os sistemas de ensino e; III- núcleo de estudos integradores para enriquecimento curricular (BRASIL, 2015b).

Quanto à estrutura e currículo dos cursos de formação inicial, em nível superior previstos no capítulo $V$ estes terão carga horária mínima de 3.200 horas de efetivo trabalho acadêmico, em cursos com duração de, no mínimo oito semestres ou quatro anos, assim distribuídos: 400 horas de prática como componente curricular, distribuída ao longo do processo formativo; 400 horas dedicadas ao estágio supervisionado; 2.200 horas dedicadas às atividades formativas estruturadas pelos núcleos I e II; 200 horas de atividade teóricopráticas de aprofundamento em áreas especifica de interesse dos estudantes, conforme núcleo III (BRASIL, 2015b).

Os cursos de formação pedagógica para graduados não licenciados terão caráter emergencial e provisório e terão carga horária

\footnotetext{
${ }^{7}$ Esse Decreto foi revogado e substituído pelo Decreto n.8.752, de 09 de maio de 2016 que dispõe sobre a Política Nacional de Formação dos Profissionais da Educação Básica.
}

mínima variável de 1.000 a 1.400 horas de efetivo trabalho acadêmico. Nessa carga horária está previsto estágio de 300 horas e 200 horas de atividades teórico-práticas de aprofundamento em área especifica de interesse do aluno. É previsto também o prazo máximo de cinco anos para o Ministério da Educação juntamente com os sistemas de ensino e os fóruns estaduais permanentes de apoio a formação docente proceder a avaliação do desenvolvimento dos cursos de formação pedagógica para graduados, bem como a definição de prazo para sua extinção (BRASIL, 2015b).

Quanto aos cursos de segunda licenciatura, terão carga horária entre 800 e 1.200 horas, a depender se pertencem ou não a mesma área do curso de origem. A carga horária de estágio é de 300 horas podendo ser reduzida em até 100 horas para portadores de diploma de licenciatura com exercício comprovado no magistério e exercendo atividade docente regular na educação básica.

O capítulo VI da Resolução orienta sobre - processo de formação continuada dos profissionais do magistério. Conforme Artigo 16

A formação continuada
compreende dimensões
coletivas, organizacionais
e profissionais, bem
como o repensar do
processo pedagógico, dos
saberes e valores, e
envolve atividades de
extensão, grupos de
estudos, reuniões
pedagógicas, cursos,
programas e ações para
além da formação
mínima exigida ao
exercício do magistério
na educação básica,
tendo como principal
finalidade a reflexão
sobre a prática
educacional e a busca de
aperfeiçoamento técnico,
pedagógico, ético e
político do profissional
docente (BRASIL, 2015b).

Trata-se de cursos que promoverão a atualização e desenvolvimento profissional constante dos profissionais do magistério, conforme as necessidades decorrentes da prática educativa, e ao acompanhamento do 
desenvolvimento da ciência e tecnologia na área de atuação. A formação continuada será ofertada por meio de atividades formativas e cursos de atualização, extensão, aperfeiçoamento, especialização, mestrado e doutorado que agreguem novos saberes e práticas, articulados às políticas e gestão da educação, à área de atuaçã̃o do profissional e às instituições de educação básica, em suas diferentes etapas e modalidades da educação (BRASIL, 2015b, Art.17). As DCNS estabelecem que a instituição formadora defina em seu projeto institucional como ocorrerá a formação continuada dos profissionais do magistério da educação básica e para tanto, deverá articular-se ao planejamento estratégico do Fórum Estadual Permanente de Apoio à Formação Docente, aos sistemas e redes de ensino e as instituições de educação básica.

O capítulo VII da resolução trata especificamente das políticas de valorização dos profissionais do magistério definindo entre outras questões, a formação inicial e continuada, planos de carreira, carga horária de trabalho destinada ao planejamento e organização da prática pedagógica, a efetiva aplicação da lei do Piso Salarial Profissional Nacional e a melhoria das condições de trabalho.

Face ao exposto, as instituições formadoras deverão fazer as adequações em sua política institucional de formação inicial e continuada de professores da educação básica conforme o estabelecido na presente diretriz, que estipulou prazo de três anos para que se faça as adaptações necessárias. É preciso, portanto, acompanhar essa política em andamento para verificar se os prazos serão cumpridos e, se realmente, as DCNS, como destaca Aguiar (2015), que representam uma conquista histórica das entidades e associações educacionais serão realmente observadas na organização dos cursos de licenciatura.

\section{CONCLUSÕES}

Ao apresentar as novas Diretrizes Curriculares Nacionais para a formação inicial e continuada dos Profissionais do Magistério da Educação Básica estabelecidas pelo Parecer CNE/CP n2/2015, e pela Resolução CNE/CP no 2/2015 buscou-se destacar que a implementação das DCNS para a formação do magistério por meio da adequação dos cursos de formação inicial e continuada se constituem em um desafio para as políticas educacionais direcionadas aos professores na atualidade, pois muitas ações precisarão ser desenvolvidas pelas instituições formativas, tanto no Ensino Superior, como na Educação Básica, para que de fato, as orientações e normatizações ali contidas, ganhem materialidade.

Entretanto, a superação desse desafio converge em implicações e/ou dificuldades significativas tanto para o Ensino Superior quanto para a Educação Básica, pressupõem a extinção do abismo que existe entre a formação acadêmica - teorizada de caráter "academicista" - com a realidade e as concretas necessidades da educação básica, pressupõem o estabelecimento do diálogo entre os dois níveis de educação a fim de se estabelecer a conexão entre esses "dois mundos".

Nesse sentido, exige-se a elaboração de planos de formação no âmbito das Universidades que não só expressem uma organização didático-pedagógica e curricular dessa formação almejada, como também uma mudança na forma como se pensam e elaboram a própria formação aos futuros professores da Educação Básica, uma vez que o que se verifica é a presença de concepções e práticas abancadas em um escopo que manifesta pouco planejamento, com objetivos imediatistas arrolados à resolução de problemas educacionais e desconectadas de um projeto único de formação nas Instituições de Ensino Superior. Fato esse que tem obtidos resultados infelizes devido ao enredamento e a multiplicidade dos problemas da educação no país: descaso com o Ensino Superior, desvalorização da profissão docente, mudanças de gestão sem a continuidade de ações e programas, ausência de um financiamento adequado para dar conta das demandas e mazelas que ainda permanecem.

Logo, é primordial que se entenda que para a compreensão e definição da política de formação de professores faz-se necessário posicioná-la em um espaço coalhado por um sistema de ideias diversas, concepções culturais, políticas e educacionais. Exceto isso, é preciso ainda que haja entendimento acerca de escola, professores/gestores e de formação de professores da Educação Básica.

Somando-se a essas discussões e análise das DCNS, há ainda o alcance das metas do PNE (2014-2024) direcionadas aos profissionais da educação, a instituição do Sistema Nacional de Educação, a regulamentação do regime de 
colaboração entre a União, Estados e Municípios, o estabelecimento da Base Nacional Comum Curricular; que por serem ações expressivas, capazes de promoverem mudanças efetivas na educação e na formação de professores; promovem impactos na organização e funcionamento dos dois níveis de educação (básica e superior). Uma vez que, exigem não apenas adequações curriculares, mas também um conceito muito "peculiar" de formação docente e de profissional da educação já que se espera do egresso da formação inicial e continuada, um perfil de "trabalhador" que possua informações e habilidades decorrentes da multiplicidade de conhecimentos adquiridos em sua formação prevista e executada a partir de um projeto educativo que Ihe permita utilizar, no exercício de suas atribuições, sua destreza interdisciplinar, bem como desenvolva seu papel com "pertinência e relevância social", com ética e a devida sensibilidade extremosa e estética.

Isso significa dizer que, a adequação curricular orientada pelas Diretrizes Curriculares Nacionais tem seu alicerce nas demandas expressas pela reestruturação do capital, pelo estabelecimento das novas relações e necessidades do mercado de trabalho advindo dessa reestruturação. Não há, portanto, uma superação dos ideais neoliberais, há um reforço desses, uma reprodução da ordem estabelecida como diria Bourdieu e Passeron ${ }^{8}$ em sua tese sobre a educação enquanto reprodução social. Tal referencial formativo provocaria ou provoca no projeto educativo para formação de professores a mesma violência simbólica ${ }^{9}$ que a

\footnotetext{
${ }^{8}$ Bourdieu e Passeron, ambos professores da área das ciências Sociais na França, desenvolveram a "teoria da reprodução" baseada no conceito de violência simbólica. Para eles, toda ação pedagógica é intencionalmente uma violência simbólica enquanto imposição de um poder arbitrário, nesse caso em especial, das determinações e/ou exigências da demanda do capital. A arbitrariedade, para os autores, constitui-se na apresentação da cultura dominante como cultura geral. No caso em exposição nesse texto, a arbitrariedade consiste na apresentação de um perfil de trabalhador, seja ele, da educação ou não, como sendo o necessário, o adequado, o único aceitável para o progresso econômico e social. O "poder arbitrário" para Bourdieu e Passeron é baseado na divisão da sociedade em classes, o mesmo se aplica na situação em discussão. A ação pedagógica, segundo os autores, tende à reprodução cultural e social simultaneamente. Em nosso entendimento, a ação pedagógica formativa proposta para a formação inicial e continuada dos professores possui a mesma tendência apresentada por Bourdieu e Passeron em sua obra A reprodução. Elementos para uma teoria do sistema de ensino, publicada no ano de 1975.

9 Violência Simbólica é um conceito social elaborado por Pierre Bourdieu o qual trata de uma forma de violência executada pelo corpo sem repressão física, em que promove agravos morais e psicológicos. É uma forma de coerção que se sustenta no valimento
}

educação escolar promove no alunado quando "os obriga" de forma velada, a adotar uma cultura que não é sua.

Não estamos querendo afirmar com essas considerações que não houve ganhos ou avanços para educação com tais mudanças. Entendemos que a Resolução CNE/CP no 2 de 10 de julho de 2015, reconhece a necessidade da consolidação das normas nacionais para a formação de profissionais do magistério, bem como a indigência da superação da fragmentação das políticas públicas e a desarticulação institucional por meio do Sistema Nacional de Educação, identifica e assume como necessidade a articulação entre as Diretrizes Curriculares para formação inicial e continuada de professores, em nível superior, e as Diretrizes Curriculares da Educação Básica. 0 que pretendemos, é chamar a atenção para onde estão ancoradas tais mudanças.

Acredita-se que a âncora dessas mudanças na formação inicial e continuada dos professores ainda não reside no pressuposto de formação do professor que considere os homens como sujeitos histórico, capazes de serem os autores de suas próprias histórias (MARX; ENGELS, 1986). Não caminha pela trilha da emancipação humana. Ao contrário, vai ao encontro dos anseios formativos do capital e da sua manutenção. Por conseguinte, pensar na formação de alguém cujas habilidades thes proporcionem adaptação às necessidades do mundo do trabalho contemporâneo e capacidade de resposta às demandas estabelecidas, não parece ser equivalente a estabelecer uma formação de caráter emancipador, ou ainda como a que descrevemos acima, capaz de atender aos anseios teóricos e metodológicos do professorado.

Assim, por mais que o discurso afirme a possibilidade de articulação entre os dois níveis da educação brasileira, ainda que apresente a exigência de projetos de formação elaborados e executados pelas instituições de ensino superior e os sistemas de educação básica, envolvendo a consolidação de fóruns estaduais e distritais permanentes para apoio a formação docente, não há, por enquanto, garantias ou mesmos indicativos que a formação a ser realizada possua um caráter e um objetivo que não seja o reprodutor das desigualdades. Por isso, o escopo

de uma imposição determinada, seja esta econômica, social ou simbólica. (CUNHA; ROCHA, 2007, p. 23). 
dessa reflexão insiste em torno do alicerce em que repousa as mudanças previstas para a formação de professores, não são circunstâncias a serem definidas aleatoriamente, mas estão engendradas, como na epígrafe desse texto, defrontadas diretamente pela realidade, "legadas e transmitidas pelo passado".

\section{REFERÊNCIAS}

AGUIAR, M. A. S. Valorização dos profissionais da educação: PNE e diretrizes para a formação. In: RONCA, A. C. C.; ALVES, L. R. O Plano Nacional de Educação e o Sistema Nacional de Educação: educar para a equidade. São Paulo: Fundação Santillana, 2015. p. 241-257.

ANTUNES, R. Adeus ao trabalho?: Ensaio sobre as metamorfoses e a centralidade do mundo do trabalho. São Paulo: Cortez/Unicamp, 1995.

ANTUNES, R. Anotações sobre o capitalismo recente e a reestruturação produtiva no Brasil. In: ANTUNES, R.; SILVA, M. A. M. (Org.). O avesso do trabalho. São Paulo: Expressão Popular, 2004. p. 13-27.

ANTUNES, R. Da educação utilitária fordista à da multifuncionalidade liofilizada. In: REUNIÃO NACIONAL DA ANPED, 38, 2017. São Luis do Maranhão. Anais... São Luis do Maranhão: UFMA, 2017. p. 1-15. Disponível em: $<$ http://38reuniao.anped.org.br/programacao/2 ?field prog gt target id entityreference filter= $\underline{14}$ > Acesso em 14/10/2017.

BOURDIEU, P.; PASSERON, J. C. A reprodução. elementos para uma teoria do sistema de ensino. Rio de Janeiro: Francisco Alves, 1975.

BRASIL. Ministério da Educação e Cultura. Lei no. 9.394, de 20 de dezembro de 1996. Fixa as Diretrizes e Bases da Educação Nacional. Brasília, DF: MEC, 1996.

BRASIL. Ministério da Educação e Cultura. Lei no 10.172, de 09 de janeiro de 2001. Aprova o Plano Nacional de Educação e dá outras providências. Brasília, DF: MEC, 2001. Disponível em:

$<$ http://www.planalto.gov.br/ccivil 03/leis/leis 2001/|10172. htm>. Acesso em: 28 jan. 2017.

BRASIL. Conselho Nacional de Educação. Conselho Pleno. Parecer CNE/CP no 9, de 8 de maio de 2001. Diretrizes Curriculares Nacionais para a Formação de Professores da Educação Básica, em nível superior, curso de licenciatura, de graduação plena. Portal MEC. Brasília, DF: $\mathrm{MEC} / \mathrm{CNE} / \mathrm{CP}$, 2001. Disponível em: http://portal.mec.gov.br/cne/arquivos/pdf/009. pdf acesso em: 20 out. 2017.

BRASIL. Ministério da Educação. Conselho Nacional de Educação. Resolução CNE/CP no 1 de 18 de fevereiro de 2002. Institui Diretrizes Curriculares Nacionais para a Formação de Professores da Educação Básica, em nível superior, curso de licenciatura, de graduação plena. Portal MEC. Brasília, DF: MEC/CNE/CP, 2002. Disponível em: <http://portal.mec.gov.br/ cne/arquivos/pdf/rcp01 02.pdf>. Acesso em: 20 out. 2017.

BRASIL. Ministério da Educação. Portaria Normativa no 9, de 30 de junho de 2009. Institui o Plano Nacional de Formação dos Professores da Educação Básica. Brasília, DF: MEC, Diário Oficial da União, 2009c. Disponível em: $<$ http://portal.mec.gov.

br/dmdocuments/port_normt_09_300609.pdf>. Acesso em: 23 out. 2017.

BRASIL . Casa Civil. Lei no 13.005, de 25 de junho de 2014. Aprova o Plano Nacional de Educação PNE e dá outras providências. Brasília, DF: Casa Civil, 2014. Disponível em: <http://www.planalto.gov.br/ccivil 03/ ato2011 -2014/2014/ lei//13005.htm>. Acesso em: 22 out. 2017.

BRASIL. Conselho Nacional de Educação. Conselho Pleno. Parecer no 2/2015. Diretrizes Curriculares Nacionais para a Formação Inicial e Continuada dos Profissionais do Magistério da Educação Básica. Brasília, DF: CNE, 2015a.

BRASIL. Conselho Nacional de Educação. Conselho Pleno. Resolução no 2/2015. Define as Diretrizes Curriculares Nacionais para a formação inicial em nível superior (cursos de licenciatura, cursos de formação pedagógica para graduados e cursos de segunda licenciatura) e para a formação continuada. Brasília, DF: CNE, 2015b.

CATÁLOGO DE TESES E DISSETAÇÕES DA CAPES. 2018. Disponível em 
http://catalogodeteses.capes.gov.br/catalogoteses/\#!/ Acesso em 23 de janeiro de 2018.

CHESNAIS, F. Capitalismo de fim de século. In: COGGIOLA, O. (Org.) Globalização e socialismo. São Paulo: Xamã, 1997. p. 7-33.

CUNHA, A.; ROCHA, T. O preço do silêncio: mulheres ricas também sofrem violência. Vitória da Conquista, BA: Edições Uesb, 2007.

DOURADO, L. F. Diretrizes Curriculares Nacionais para a formação inicial e continuada dos profissionais do magistério da educação básica: concepções e desafios. Educação \& Sociedade, Campinas, v. 36 , n. 131 , p. 299-324, abr./jun., $2015 . \quad$ Disponível em: https://doi.org/10.1590/ES0101$\underline{73302015151909}$

DOURADO, L. F. A Formação inicial e continuada de profissionais do magistério da Educação Básica. In: RONCA, A. C. C.; ALVES, L. R. O Plano Nacional de Educação e o Sistema Nacional de Educação: educar para a equidade. São Paulo: Fundação Santillana, 2015b. p. 259-282.

FREITAS, H. C. L. Formação de professores no Brasil: 10 anos de embates entre projetos de formação. Educação \& Sociedade, Campinas, SP, v. 23 , n. 80 , p. 136-167, set. 2002. Disponível em: https://doi.org/10.1590/s0101-

\section{9}

FREITAS, H. C. L. A (nova) política de formação de professores: a prioridade postergada. Educação \& Sociedade, Campinas, SP, v. 28, n. 100, Especial, p. 1203-1230, out. 2007.

FREITAS, H. C. L. A construção do sistema nacional de formação e valorização dos educadores: unitário, organicamente articulado e plural. In: PINO, I. R.; ZAN, D. D. P. (Org.). Plano Nacional da Educação (PNE): questões desafiadoras e embates emblemáticos. Brasília, DF: INEP, 2013. p. 229-249.

HARVEY, David. Condição pós-moderna. 16. ed. São Paulo: Loyola, 1992.

KUENZER, A. Z. Trabalho e escola: a aprendizagem flexibilizada. In: REUNIÃO CIENTÍFICA REGIONAL DA ANPED SUL, 11, 2016. Curitiba. Anais... Curitiba: UFPR, 2016. p. 1-22.
MARX, K. 018 brumário de Luiz Bonaparte. São Paulo: Centauro, 2003.

MARX, K.; ENGELS, F. A ideologia alemã. 5. ed. Tradução de José Carlos Bruni e Marco Aurélio Nogueira. São Paulo: Hucitec, 1986.

MÉSZÁROS, I. Para além do capital. Tradução de Paulo Cezar Castanheira e Sérgio Lessa. Campinas, São Paulo: Boitempo, 2002.

MOREIRA, J. A. S; LARA, A. M. B. Políticas públicas para a educação infantil no Brasil (1990-2001). Maringá: Eduem, 2012.

MOREIRA, J. A. S. Políticas de financiamento e gestão da educação básica (1990-2010): os casos Brasil e Portugal. Maringá: EDUEM, 2015. Disponível em: https://doi.org/10.7476/9788576286547

SHIROMA, E. O.; CAMPOS, R. F.; GARCIA, R. M. C. Decifrar textos para compreender a política: subsídios teórico-metodológicos para análise de documentos. Perspectiva, Florianópolis, v.23, n.2. p. 427-446, jul./dez. 2005.

SILVA JÚNIOR, J. R. The new brazilian university: a busca por resultados comercializáveis: para quem? Bauru: Canal 6. 2017.

SOARES, L. T. O desastre social. Rio de Janeiro: Record, 2003.

SCHEIBE, L.; BAZZO, V. L. Diretrizes Curriculares Nacionais para os Cursos de Licenciatura no Brasil: da regulamentação aos Projetos Institucionais. Educação em Perspectiva, Viçosa, v. 4, n. 1, p. 15-36, jan./jun. 2013.

TOUSSANINT, E. A bolsa ou a vida: a dívida externa do terceiro mundo: as finanças contra os povos. São Paulo: Fundação Perseu Abramo, 2002.

Recebido para publicação em: 03/11/2017

Revisado em: 30/01/2018

Aceito em: 09/03/2018 